\title{
Lymphocyte Recirculation: A Brief Review
}

\author{
Veronika P. Patrakeeva, PhD* \\ N. Laverov Federal Center for Integrated Arctic Research RAS (FCIArctic RAS) \\ Arkhangelsk, the Russian Federation
}

\begin{abstract}
This brief review provides up-to-date information on the study of lymphocyte recirculation, in particular, the main mechanisms and factors of an exogenous and endogenous nature, affecting the activity of lymphocyte recirculation and migration. (International Journal of Biomedicine. 2019;9(4):382-385.)
\end{abstract}

Key Words: lymphocyte recirculation • lymph node • immunocompetent cells

\section{Abbreviations}

APCs, antigen-presenting cells; HEVs, high endothelial venules; LN, lymph node; LR, lymphocyte recirculation

$\mathrm{R}$ ecirculation is an essential process of continuous transport of immunocompetent cells between the lymphoid system and the blood, providing proper immunological control. The ability to recirculate is characteristic only of lymphocytes. Naive cells, using the circulatory and lymphoid systems as transport routes, continuously migrate between lymphoid and non-lymphoid organs and tissues. ${ }^{(1,2)}$ During recirculation, the remaining naive lymphocytes are found in the secondary lymphoid tissues for about 10-20 hours. If there is no interaction with the antigen on the corresponding antigen-presenting cells (APCs), the cells exit through the efferent lymph ducts, eventually drain into the lymphatic system of the thoracic duct and reunite with the blood, and continue to recirculate throughout life. However, if the immune response is initiated in the CD4+ T-cell population by presenting with APC a peptide antigen associated with MHC class II, a change in the characteristic pattern of recycling occurs. Almost immediately after infection with an antigen, lymphocytes remain at this site for a day or more, ${ }^{(3)}$ which is called a shutdown of the CD4 T-cell response. Recycling of lymphocytes into the secondary lymphoid organs is an important process in immunological

"Corresponding author: Veronika P. Patrakeeva, PhD. Head of the Department of Environmental Immunology, N. Laverov Federal Center for Integrated Arctic Research RAS (FCIArctic RAS). Arkhangelsk, the Russian Federation. Email: patrakeewa.veronika@yandex.ru surveillance and significantly increases the likelihood that antigen-specific $\mathrm{T}$ and $\mathrm{B}$ cells will encounter related antigens. The exception is the brain: due to the presence of the bloodbrain barrier, it is considered that the brain is subject to limited immunological surveillance. ${ }^{(4,5)}$ However, for example, under the influence of a strong stress factor, endothelial cells of the brain vessels are transformed, resulting in increased expression of cell adhesion molecules that facilitate the adhesion and extravasation of immunocompetent cells. The cells penetrating the brain change their phenotype and begin to produce predominantly pro-inflammatory cytokines, which leads to the initiation of an inflammatory response in the structures of the brain - neuroinflammation, accompanied by an increase in the manifestations of the anxiety-depressive state. $^{(6-11)}$

Lymphocyte recirculation (LR) depends on the anatomical origin of the cells, the presence of inflammation and pro-inflammatory cytokines, adhesion molecules and the presence of receptors on the cells to these adhesion molecules. In LR, both continuously expressed and, in some cases, tissuespecific adhesion receptors are used. This allows resting lymphocytes to continuously move through tissue components, optimizing the effect on isolated antigens. Naive T lymphocytes recycle most efficiently through the peripheral lymph nodes (LNs), where there is an effective processing, concentration and presentation of foreign antigens. Having various surface receptors, various subpopulations of lymphocytes differ 
significantly in their adhesive characteristics, so $\mathrm{T}$ cells with a phenotype of memory cells penetrate into inflammatory foci more easily than naive cells. Thus, the most efficiently responding cell population is directed to areas of potentially active disease. Specific LR occurs back into the tissue in which they were activated. Thus, memory lymphocytes activated in the mesenteric LNs are located mainly in the intestine, while lymphocytes activated in the axillary LNs return to the skin, and lymphocytes stimulated in Peyer's patches pass through the regional LNs into the bloodstream, and then return "home"in lamina propria of the mucous membrane. This specific recirculation is ensured by the presence of specific homing molecules on the surface of lymphocytes that bind to adhesion molecules (addressins) on the surface of the endothelial cells of venules of lymphoid tissue of the mucous membranes. The endothelium serves as a critical separation between the tissues and adjacent circulatory lymphatic sections. Activated immunoblasts (memory cells or effectors) recycle to areas of the mucous membrane, while small lymphocytes (naive cells) return to the lymphoid organs. ${ }^{(12)}$ Moreover, the LR activity, for example, in the thymus, depends on age: it is higher in children than in adults and increases again in the elderly. ${ }^{(13)}$ In children, $5 \%-15 \%$ of $\mathrm{CD} 4+$ thymocytes are of peripheral origin. It is believed that the recycling of mature CD4+ cells from the periphery to the thymus increases the differentiation of thymic epithelial cells (TEC) precursors to mTEC, ${ }^{(14)}$ which leads to depletion of TEC precursors and promotes the involution of the thymus.Regulatory $\mathrm{T}$ (Treg) cells expressing the transcription factor Foxp3 are also actively recycled to the thymus. Thus, activated lymphocytes migrating into the thymus and APCs from the periphery can influence the development and differentiation of $\mathrm{T}$ lymphocytes and participate in the process of thymus involution. ${ }^{(15)}$ However, the molecular mechanisms of the process of penetration of cells into the thymus, as well as their exact functions, have not yet been fully determined. Penetration of lymphocytes into LNs or Peyer's patches is achieved by transmigration through HEVs. HEVs carry many unique adhesion molecules that capture lymphocytes. They also have special intercellular connections that facilitate the penetration of the walls of blood vessels by these emigrating lymphocytes. The endothelium plays an essential, locally tuned role in regulating $\mathrm{T}$ cell migration and information exchange. Intimate cell-cell interaction between lymphocytes and endothelial cells provides instruction to $\mathrm{T}$ cells that influences their states of activation and differentiation. In addition, the endothelium can act as a non-hematopoietic, "semiprofessional," antigen-presenting cell. Close contacts between circulating $\mathrm{T}$ cells and antigen-presenting endothelium may play unique non-redundant roles in shaping adaptive immune responses within the periphery. ${ }^{(16)}$ The main factors regulating the dynamic transfer of lymphocytes are members of the chemokine family, as well as lipid mediator sphingosine-1phosphate (SIP). They perform this control by activating specific receptors, which contribute to the adhesion of lymphocytes inside specific microvessels of the secondary lymphatic organs, and subsequent migration within the lymphoid tissue, and exit into the blood. ${ }^{(17)}$ Lymphocyte egress from LNs is strongly dependent on sphingosine-1-phosphate receptor type
1 (S1PR1), by which lymphocytes sense high concentration of S1P in lymph $(\sim 100 \mathrm{nmol} / \mathrm{L})$ compared with $\mathrm{LN}$ parenchyma $(\sim 1 \mathrm{nmol} / \mathrm{L})$ to exit LN. S1PR1 acts to overcome retention signals mediated by CCR7, CXCR4 and possibly additional chemoattractant receptors. ${ }^{(18,19)}$

The migration of lymphocytes from HEVs into lymphoid organs is ensured by the sequence of interactions between the cell adhesion molecules on the lymphocytes and the vascular endothelial cell molecules that line the vessels. At the same time, lymphocyte homing receptors and vascular adresants regulate the first stages of this process - lymphocyte binding. Subsequent movement of lymphocytes along the surface of endothelial cells and migration through the vessel wall (diapedesis) are regulated regardless of the initial binding. It is assumed that these last stages are mediated by the functional activation of integrins on the lymphocyte by chemoattractants located in the vessel wall. ${ }^{(20)}$

Brezinschek et al. ${ }^{(21)}$ showed that $\mathrm{CD} 4+\mathrm{T}$ cells acquire the capacity for transendothelial migration at a specific phase of maturation that is only minimally altered by the activation of either the T cell or the endothelial cells, or by the presence of specific chemokines in the subendothelial matrix.

Immunocompetent cells differ significantly in their adhesive properties, so analysis of $\mathrm{T}$ helper-cell subsets revealed that memory $\mathrm{T}$ cells bound severalfold stronger to ICAM-1 expressing transfectants compared to the CD4+ 45RA+ naive $\mathrm{T}$ cells, whereas adhesion to B7, LFA-3- and B7/LFA-3-expressing CHO cells was similar in both T-cell subsets. ${ }^{(22)}$ Authors suggest that resting naive $\mathrm{CD} 4+\mathrm{T}$ cells utilize preferentially the CD2/LFA-3 or CD28/B7 adhesion pathways upon adhesion to APCs, while memory CD4+ T cells utilize the CD2/LFA-3, CD28/B7 and LFA-1/ICAM-1 adhesion pathways. ${ }^{(22)}$

Stress hormones, cytokines, prostaglandins, and heavy metals capable of changing the adhesion properties of cells influence lymphocyte recycling. C. Spry showed that the administration of corticotropin reduces the egress of lymphocytes from the thoracic duct. In particular, their recirculation to the lymph decreased, and a smaller amount was restored. ${ }^{(28)}$ Adrenergic regulation of the level of lymphocytes causes a decrease in the number of lymphocytes in the blood (which is associated with inhibition of the egress from LNs of antigen-primed memory $\mathrm{T}$ cells, but not effector cells), which is associated with the predominant expression of $\beta 2 \mathrm{AR}$ memory by $\mathrm{T}$ cells. ${ }^{(29-31)}$ High adrenergic nerve activity can promote the priming of lymphocytes in the $\mathrm{LN}$, but inhibit the inflammation caused by lymphocytes in the peripheral tissues. ${ }^{(32-34)}$ A decrease in the activity of adrenergic nerves allows lymphocytes to leave LNs and gain access to peripheral tissues, which will facilitate the recognition and elimination of pathogens at the sites of infection. Consequently, adrenergic nerves can coordinate adaptive immune responses in LNs and peripheral tissues in order to maximize the host's defense effectiveness by generating a daily LR rhythm. ${ }^{(35)}$

Zalavina et al. ${ }^{(36)}$ studied the structural features of the zonal and cellular organization of thymus in 20 pregnant Wistar rats with the introduction of cadmium. The revealed morphological restructuring of the thymus indicated the 
accidental involution of the thymus, increased processes of death of thymocytes, and violation of the permeability of the components of the hematological barrier. The lymphocyte migration coefficient through individual postcapillary venules was reduced; however, the number of post-capillary venules involved in the process of effective migration increased, and this ensures the maintenance of recirculation processes of lymphoid cells at a sufficient level.

Lymphocyte egress from LNs is an important therapeutic target in T-cell-mediated autoimmune disease. ${ }^{(37)}$ The presence of a viral antigen in LNs and spleen leads to a change in the rate of LR due to an increase in the average rate of T-cell binding (adhesion) to dendritic cells, and to a decrease in the rate of dissociation. This mechanism of the extreme retention of lymphocytes in lymphoid tissue through changes in the adhesive properties of APCs is probably also responsible for the lymphocyte shutdown phenomenon, in which the egress of lymphocytes from the antigen-stimulated LN can be temporarily stopped. ${ }^{(38)}$ In addition, in some chronic inflammatory conditions, the formation of HEV-like vessels is induced, for example, with chronic Helicobacter pylorigastritis, inflammatory bowel disease and autoimmune pancreatitis, as well as with lymphoid stroma formed in some types of tumors. In these cases, activating factors include bacterial products (e.g., lipopolysaccharides) and pro-inflammatory cytokines (IL-1, TNF $\alpha$, IFN $\gamma$ ). This allows for LR (homing), similar through HEVs to the secondary lymphoid organs. In the diffuse sclerosing variant of papillary thyroid cancer, the dominant population of cells attached to the surface of HEV-like vessels was CD8+ lymphocytes. With Hashimoto thyroiditis, there were no significant differences in the number of $\mathrm{T}$ and B cells. Such differences in the binding of lymphocytes to HEV-like vessels in various pathological conditions can be associated with various chemokines acting on these vessels. ${ }^{(39)}$ It has been shown that FTY720 inhibits the egress of autoreactive $\mathrm{T}$ cells from the $\mathrm{LN}$ and, therefore, their migration to the target organ.(40) Animal studies have shown that treatment with $\beta 2 \mathrm{AR}$ agonists suppresses experimental autoimmune encephalomyelitis. ${ }^{(41-43)}$ In sepsis, the number of lymphocytes in the peripheral blood decreases, mainly due to increased recycling of CD4+ cells. ${ }^{(44)}$

Thus, the study of LR is important for understanding the course of the normal immune response, as well as the formation of pathology. However, there are many unanswered questions regarding the recirculation of various subpopulations of lymphocytes and the role of humoral factors, such as cytokines, chemokines and hormones, in regulating the recycling of subpopulations of cells, and little is known about the signals that control cell retention in tissue, which also include adhesive interactions. The molecular mechanisms of the process of penetration of activated cells into the thymus, as well as their exact functions, are also not completely determined. Very little is known about the potential function of recirculating $\mathrm{T}$ cells in dampening acute immune responses, possibly via tissue exit of Tregs or of T cells with irrelevant antigenic specificities. ${ }^{(45)}$ Clarification of the molecular basis of the specific interactions of lymphocytes with endothelium will improve our understanding of the regulatory roles of adhesion molecules in other biological processes, such as the formation of immunodeficiency and metastasis. More insight into both the molecular mechanisms and the relevance of these processes will contribute to identifying new targets for immunomodulatory therapies.

\section{Competing Interests}

The author has no competing interests to declare.

\section{Sources of Funding}

This work was carried out as part of a fundamental research program on the topic of the laboratory of environmental immunology by the FCIARctic project № AAAA-A17-117033010124-7.

\section{References}

1. Miyasaka M, Hata E, Tohya K, Hayasaka H. Lymphocyte Recirculation. Encyclopedia of Immunobiology. 2016;3:486-492. 2. Cyster JG, Schwab SR. Sphingosine-1-phosphate and lymphocyte egress from lymphoid organs. Annu Rev Immunol. 2012;30:69-94. doi: 10.1146/annurevimmunol-020711-075011.

3. Mackay CR, Marston W, Dudler L. Altered patterns of $\mathrm{T}$ cell migration through lymph nodes and skin following antigen challenge.Eur J Immunol. 1992;22(9):2205-10.

4. Smith ME, Sommer MA. Association between cellmediated demyelination and astrocyte stimulation. Prog Brain Res. 1992;94:411-22.

5. Brown KA. Factors modifying the migration of lymphocytes across the blood-brain barrier. Int Immunopharmacol. 2001.1(12):2043-62.

6. Cohen H, Matar MA, Zohar J. Maintaining the clinical relevance of animal models in translational studies of posttraumatic stress disorder. ILAR J. 2014;55(2):233-45. doi: 10.1093/ilar/ilu006.

7. Cohen S, Janicki-Deverts D, Doyle WJ, Miller GE, Frank E, Rabin BS, Turner RB. Chronic stress, glucocorticoid receptor resistance, inflammation, and disease risk. Proc Natl Acad Sci USA. 2012;109(16):5995-9. doi: 10.1073/ pnas. 1118355109 .

8. Cole SW, Hawkley LC, Arevalo JM, Cacioppo JT. Transcript origin analysis identifies antigen-presenting cells as primary targets of socially regulated gene expression in leukocytes. Proc Natl Acad Sci USA. 2011;108(7):3080-5. doi: $10.1073 /$ pnas. 1014218108 .

9. Ramirez K, Niraula A, Sheridan JF. GABAergic modulation with classical benzodiazepines prevent stressinduced neuro-immune dysregulation and behavioral alterations. Brain Behav Immun. 2016;51:154-68. doi: 10.1016/j.bbi.2015.08.011.

10. Wohleb ES, Powell ND, Godbout JP, Sheridan JF. Stress-induced recruitment of bone marrow-derived monocytes to the brain promotes anxiety-like behavior. J Neurosci. 2013;33(34):13820-33. doi: 10.1523/ JNEUROSCI.1671-13.2013.

11. Kondashevskaya MV. [Characteristics of the structural organization of spleen tissue in modeling post-traumatic stress disorder]. Vestnik novykh meditsinskikh tekhnologiy. Elektronnoye izdaniye. 2018;(5):51-56. [Article in Russian]. 
12. Yu W, Nagaoka H, Jankovic M, Misulovin Z, Suh H, Rolink A, Melchers F, Meffre E, Nussenzweig MC. Continued RAG expression in late stages of B cell development and no apparent re-induction after immunization. Nature. 1999;400(6745):682-7.

13. Surh CD, Sprent J, Webb SR. Exclusion of circulating T cells from the thymus does not apply in the neonatal period. J Exp Med. 1993;177(2):379-85.

14. Yin C, Pei XY, Shen H, Gao YN, Sun XY, Wang W, Ge Q, Zhang Y. Thymic homing of activated CD4+ T cells induces degeneration of the thymic epithelium through excessive RANK signaling. Sci Rep. 2017;7(1):2421. doi: 10.1038/ s41598-017-02653-9.

15. Santamaria J, Darrigues J, van Meerwijk JPM, Romagnoli P. Antigen-presenting cells and T-lymphocytes homing to the thymus shape T cell development. Immunol Lett. 2018;204:915. doi: 10.1016/j.imlet.2018.10.003.

16. Carman $\mathrm{CV}$, Martinelli R. Lymphocyte-Endothelial Interactions. Encyclopedia of Cell Biology. 2016;3:632-649.

17. Nombela-Arrieta C. Intracellular signaling pathways mediating lymphocyte trafficking. Inmunologia. 2008;27(4):192-204.

18. Pham TH, Okada T, Matloubian M, Lo CG, Cyster JG. S1P1 receptor signaling overrides retention mediated by $G$ alpha $\mathrm{i}$-coupled receptors to promote $\mathrm{T}$ cell egress. Immunity. 2008;28(1):122-33. doi: 10.1016/j.immuni.2007.11.017.

19. Schmidt TH, Bannard O, Gray EE, Cyster JG. CXCR4 promotes B cell egress from Peyer's patches. J Exp Med. 2013;210(6):1099-107. doi: 10.1084/jem.20122574.

20. Ager A. Lymphocyte recirculation and homing: roles of adhesion molecules and chemoattractants. Trends Cell Biol. 1994;4(9):326-33.

21. Brezinschek RI, Lipsky PE, Galea P, Vita R, OppenheimerMarks N. Phenotypic characterization of CD4+ T cells that exhibit a transendothelial migratory capacity. J Immunol. 1995;154(7):3062-77..

22. Parra E, Wingren AG, Hedlund G, Sjögren HO, Kalland T, Sansom D, Dohlsten M. Human naive and memory T-helper cells display distinct adhesion properties to ICAM-1, LFA-3 and B7 molecules. Scand J Immunol. 1993;38(6):508-14.

23. Blackwell TS, Christman JW. Sepsis and cytokines: current status. Br J Anaesth. 1996;77(1):110-7.

24. Sarlis NJ, Chanock SJ, Nieman LK. Cortisolemic indices predict severe infections in Cushing syndrome due to ectopic production of adrenocorticotropin. J Clin Endocrinol Metab. 2000;85(1):42-7.

25. Pabst R, Westermann J. Which steps in lymphocyte recirculation are regulated by interferon-gamma? Res Immunol. 1994;145(4):289-94.

26. Repina VP. The effect of catecholamines on the level of immunoglobulins and cytokines in the blood. Russian Journal of Allergy. 2008;(1):242-243.

27. Dobrodeeva LK, Patrakeeva VP. The influence of migration and proliferative processes of lymphocytes on the state of the immune body of a person living in high latitudes. Ekaterinburg. LLC "Interregional Publishing Center"; 2018. [In Russian].

28. Spry CJ. Inhibition of lymphocyte recirculation by stress and corticotrophin. Cell Immunol. 1972;4(1):86-92.

29. Benschop RJ, Rodriguez-Feuerhahn M, Schedlowski M. Catecholamine-induced leukocytosis: early observations, current research, and future directions. Brain Behav Immun.
1996;10(2):77-91.

30. Sanders VM.The beta2-adrenergic receptor on $\mathrm{T}$ and $\mathrm{B}$ lymphocytes: do we understand it yet? Brain Behav Immun. 2012;26(2):195-200. doi: 10.1016/j.bbi.2011.08.001.

31. Nakai A, Hayano Y, Furuta F, Noda M, Suzuki K. Control of lymphocyte egress from lymph nodes through $\beta 2$ adrenergic receptors. J Exp Med. 2014;211(13):2583-98. doi: 10.1084/jem.20141132.

32. Haus E, Smolensky MH. Biologic rhythms in the immune system. Chronobiol Int. 1999;16(5):581-622.

33. Scheiermann C, Kunisaki Y, Lucas D, Chow A, Jang JE, Zhang D, et al. Adrenergic nerves govern circadian leukocyte recruitment to tissues. Immunity. 2012;37(2):290-301. doi: 10.1016/j.immuni.2012.05.021.

34. Suzuki S, Toyabe S, Moroda T, Tada T, Tsukahara A, Iiai T, et al. Circadian rhythm of leucocytes and lymphocytes subsets and its possible correlation with the function of the autonomic nervous system. Clin Exp Immunol. 1997;110(3):500-8.

35. Nakai A, Suzuki K. Adrenergic control of lymphocyte trafficking and adaptive immune responses. Neurochem Int. 2019;130:104320. doi: 10.1016/j.neuint.2018.10.017.

36. Zalavina SV, Elyasin PA, Salomeina NV, Samatova IM, Mashak SV, Popp EA, Dubinina NN. Influence of cadmium on cytoarchitectonics and lymphocyte recirculation processes in the thymus during pregnancy. Sibirskii Medizinskii Vestnik. 2018;(1):14-18

37. Steinman L. Immunology of relapse and remission in multiple sclerosis. Annu Rev Immunol. 2014;32:257-81. doi: 10.1146/annurev-immunol-032713-120227.

38. Stekel DJ. The role of inter-cellular adhesion in the recirculation of T lymphocytes. J Theor Biol. 1997;186(4):491-501.

39. Low S, Sakai Y, Hoshino H, Hirokawa M, Kawashima $\mathrm{H}$, Higuchi $\mathrm{K}$, et al. High endothelial venule-like vessels and lymphocyte recruitment in diffuse sclerosing variant of papillary thyroid carcinoma. Pathology. 2016;48(7):666-674. doi: 10.1016/j.pathol.2016.08.002.

40. Brinkmann V, Billich A, Baumruker T, Heining P, Schmouder R, Francis G, et al. Fingolimod (FTY720): discovery and development of an oral drug to treat multiple sclerosis. Nat Rev Drug Discov. 2010;9(11):883-97. doi: $10.1038 /$ nrd3248.

41. Chelmicka-Schorr E, Kwasniewski MN, Thomas BE, Arnason BG. The beta-adrenergic agonist isoproterenol suppresses experimental allergic encephalomyelitis in Lewis rats. J Neuroimmunol. 1989;25(2-3):203-7.

42. Wiegmann K, Muthyala S, Kim DH, Arnason BG, Chelmicka-Schorr E. Beta-adrenergic agonists suppress chronic/relapsing experimental allergic encephalomyelitis (CREAE) in Lewis rats. J Neuroimmunol. 1995;56(2):201-6. 43. Nakai A, Hayano Y, Furuta F, Noda M, Suzuki K. Control of lymphocyte egress from lymph nodes through $\beta 2$ adrenergic receptors. J Exp Med. 2014;211(13):2583-98. doi: 10.1084/jem.20141132.

44. Holub M, Klucková Z, Beneda B, Hobstová J, Huzicka I, Prazák J, Lobovská A. Changes in lymphocyte subpopulations and $\mathrm{CD} 3+/ \mathrm{DR}+$ expression in sepsis. Clin Microbiol Infect. 2000;6(12):657-60.

45. Hunter MC, Teijeira A, Halin C. T Cell Trafficking through Lymphatic Vessels. Front Immunol. 2016;7:613. doi: 10.3389/fimmu.2016.00613. eCollection 2016. 